\title{
Key Role of Post-emptive PPAR- $\gamma$ Activation in Extenuating Pain Hypersensitivity in Mononeuropathic Rats
}

\author{
Seema Thakur ${ }^{1, \#, ~ H a r i t h a ~ P a s u p u l a t i ~}{ }^{2, \#, ~ S h r i n i v a s ~ K r i s h n a r a o ~ K u l k a r n i ~}{ }^{3}$, Satyanarayana Siddhi Venkata Padi 1,4,* \\ 'Department of Pharmacology, ISF College of Pharmacy, Moga, Punjab, INDIA. \\ 2Department of Pharmacology, Bharat Institute of Technology-Pharmacy, Hyderabad, Telangana, INDIA \\ ${ }^{3}$ Department of Pharmacology, University Institute of Pharmaceutical Sciences, Panjab University, Chandigarh, INDIA. \\ ${ }^{4}$ Department of Pharmacology, Jangaon Institute of Pharmaceutical Sciences, Jangaon, Telangana, INDIA. \\ "These authors contributed equally
}

\begin{abstract}
Background: Neuropathic pain, a chronic debilitating painful condition, is frequently difficult to manage with the conventional analgesics. Emerging evidence indicates potential role of peroxisome proliferator-activated receptor (PPAR)- $\gamma$, a subfamily of nuclear receptors, in regulating inflammation and oxidative stress at transcription level. Therefore, we investigated whether activation of PPAR- $\gamma$ attenuate established neuropathic pain and to delineate underlying mechanisms. Methods: Neuropathy was induced by chronic constriction injury of sciatic nerve in rats. Behavioral tests were performed to assess pain hypersensitivity and the markers of inflammation and nitroso-oxidative stress were estimated in sciatic nerve. Results: Chronic administration of pioglitazone (10 and $30 \mathrm{mg} / \mathrm{kg}$, i.p.) for 2 weeks starting 14 days after nerve injury did not induce hypoalgesia in contralateral paws and had no effect on locomotor activity. However, pioglitazone significantly mitigated cold allodynia and thermal hyperalgesia in ipsilateral paws after nerve injury. In addition, pioglitazone reduced plasma extravasation and pro-inflammatory cytokines, TNF- $\alpha$ and IL-1 $\beta$, following nerve injury. These effects of pioglitazone are parallel with the significant reduction in lipid peroxidation, protein carbonyls, nitrite levels as well as marked
\end{abstract}

improvement in GSH and activities of SOD, catalase in injured nerves. BADGE, a PPAR $\gamma$ antagonist (30 mg/ $/ \mathrm{kg}$, i.p.) reversed the effects of pioglitazone in chronic constriction injury (CCI) rats. Conclusion: Together, the present results demonstrate that activation of PPAR- $\gamma$ receptor-dependently exerted antiallodynic and antihyperalgesic effects through inhibition of inflammation and nitroso-oxidative stress in mononeuropathic rats and supporting a key role of PPAR- $\gamma$ activation in extenuating existing neuropathic pain

Key words: BADGE, Chronic constriction injury, Nerve injury, Neuroinflammation, Neuropathic pain, Pain hypersensitivity, Pioglitazone, PPAR- $\gamma$ agonist.

Correspondence

Dr. Satyanarayana SV Padi,

Professor, Department of Pharmacology, Jangaon Institute of Pharmaceutical Sciences, Jangaon-506167, Telangana, INDIA.

Email id: ssvpadi@gmail.com

DOI: 10.5530/ijpi.2021.3.55

\section{INTRODUCTION}

Neuropathic pain is a type of chronic pain caused by a lesion or disease of the somatosensory nervous system and represents a various pain syndromes of diverse etiologies. It is estimated that its prevalence in the general population may be as high as 7 to $8 \%$ accounting for 20 to $25 \%$ of individuals with chronic pain which is characterized by pain hypersensitivities such as allodynia and hyperalgesia. ${ }^{1}$ Neuropathic pain disables the person, affects quality of life, and a potential cause for global burden. ${ }^{2}$ Currently, available therapies for neuropathic pain provide symptomatic relief with poor response rate and often associated with resistance, and dose-limiting side effects. ${ }^{2,3}$ As a result, it is essential to develop novel therapeutic strategies in treating neuropathic pain.

The pharmacological management of neuropathic pain is further hampered due to the complexity and poor understanding of its pathophysiology. Owing to advances in neurobiology of pain, understanding of the cellular and molecular mechanism involved in neuropathic pain has markedly evolved. It is originally believed that neuropathic pain originates from and involves only sensory neuronal sensitization. Growing body of evidence indicates non-neuronal cells, such as immune cells in the periphery and glia cells in the CNS also contribute to neuropathic pain. ${ }^{4,5}$ Indeed, nerve injury induces a cascade of immune responses that involves activation of non-neuronal cells and neuro-immune communication. ${ }^{6}$ Further, activated macrophages in the periphery and glial cells in the spinal cord release chemokines and pro-inflammatory cytokines, such as tumor necrosis factor (TNF)- $\alpha$, interleukin (IL)-1 $\beta$, and IL- 6 resulting in the induction, development, and sustained maintenance of neuropathic pain state. ${ }^{6,7}$

The pathogenesis of neuropathic pain is strongly linked to free radical release, oxidative and nitrosative stress. ${ }^{8,9}$ Accumulating data suggests that nerve injury-induced alterations in mitochondrial bioenergetics increase reactive oxygen species (ROS) release with diminished antioxidant defense system in cells. Adding to this, oxidative stress and nitric oxide after nerve injury sensitively modulate various neurophysiological processes and sensory nociceptive receptors leading to neuropathic pain through sensitization of the nociceptive. ${ }^{10,11}$

Peroxisome proliferator-activated receptors (PPAR) $-\gamma$ are a subfamily nuclear transcription factors that belongs to ligand activated nuclear receptor superfamily. Upon ligand activation, the PPAR:retinoid X receptor (PPAR/RXR) heterodimers bound to peroxisome proliferator response elements (PPREs) in the regulatory region of their target genes, and recruit specific co-factors, thereby modulate target genes. ${ }^{12}$ Indeed, PPAR- $\gamma$ ligand binding to its receptors leads to transactivation and transrepression to exert their functions. Of note, PPAR- $\gamma$ control glucose metabolism and inflammation and PPAR- $\gamma$ agonists, such as rosiglitazone and pioglitazone, among others are widely used for their immunomodulation and insulin-sensitization in the management of type- 2 diabetes 
mellitus. ${ }^{12,13}$ Also, PPAR- $\gamma$ activation regulates redox state, antioxidant defenses, and inflammation. ${ }^{13}$ Moreover, PPAR- $\gamma$ activation has been shown to exert anti-inflammatory and neuroprotective effects in chronic pain, spinal cord injury, and neurodegenerative disorders. ${ }^{14,15}$ These properties of PPAR- $\gamma$ strongly suggest that it could be a potential target for modulating neuropathic pain. Nevertheless, role of PPAR- $\gamma$ activation in traumatic neuropathic pain is not fully known.

Thus, the present study investigated whether PPAR- $\gamma$ activation attenuates established neuropathic pain hypersensitivities following chronic constriction (CCI) injury and attempted to delineate the underlying mechanisms.

\section{MATERIALS AND METHODS}

\section{Experimental animals}

Wistar rats (160-200 g) of either sex were housed under standard conditions of light and dark cycle in the Central Animal House of I.S.F College of Pharmacy, Moga, India with food and water ad libitum. Animals were acclimatized to laboratory conditions before the behavioral tests. All experiments were carried between 08:00 and 16:00 hr. The experimental protocols were approved by the Institutional Animal Ethics Committee (CPPU/0508/PTMP-PCS/1008/7) and were carried out in accordance with the guidelines of the Indian National Science Academy for the use and care of experimental animals. Each animal was used for a single treatment and each group consisted of six to eight animals and they were placed in group of three in each polypropylene plastic cage after surgery with husk bedding.

\section{Drugs and chemicals}

Pioglitazone hydrochloride (Dr. Reddy's Labs, India), BADGE (bisphenol A diglycidyl ether) (Sigma-Aldrich Corporation, India), and Evans blue (EB) were used in this study. Rat TNF- $\alpha$ and IL- $1 \beta$ ELISA kits (R\&D systems, MN, USA) were used to quantify cytokines. Unless stated, all other chemicals and biochemical reagents of highest analytical quality were used. Pioglitazone for intraperitoneal (i.p.) administration was freshly prepared by suspending in one or two drops of Tween 80 in normal saline. BADGE was dissolved in ethanol and diluted with 1:20 ethanol CMC (1.5\% w/v in saline). The solutions were administered $0.5 \mathrm{~mL}$ per $100 \mathrm{~g}$ rat. Evans blue was dissolved in normal saline.

\section{Chronic constriction injury (CCl) model of neuropathic pain}

The unilateral mononeuropathy was produced according to the method described by Bennett and Xie. ${ }^{16}$ Briefly, the rats were anesthetized using thiopental sodium (30 mg/kg, i.p.) and blunt dissection through the biceps femoris muscle at the level of the middle of the left thigh was done to expose the common sciatic nerve. Approximately 7-mm of sciatic nerve proximal to the trifurcation was freed and the sciatic nerve was ligated four times with 1-mm intervals using 4-0 chromic gut. While tying the ligatures, great care was taken to avoid interrupting epineural blood flow. For sham surgery, the connective tissue was freed and sciatic nerve was not ligated. To prevent sepsis, all animals received gentamicin ( $5 \mathrm{mg} / \mathrm{kg}$, i.p.) after surgery. In this post-emptive paradigm study, body weight and locomotor activity score using actophotometer were measured on day 0 before surgery and on days 14 and 28 after surgery.

\section{Study design}

All animals were acclimatized to lab environment for at least $2 \mathrm{hr}$ before behavioral testing. The experimental protocol comprised of six groups, namely group I: sham control, group II: CCI control, group III: CCI + pioglitazone $10 \mathrm{mg} / \mathrm{kg}$, group IV: CCI + pioglitazone $30 \mathrm{mg} / \mathrm{kg}$, group V: $\mathrm{CCI}+\mathrm{BADGE} 30 \mathrm{mg} / \mathrm{kg}$, and group VI: CCI + BADGE + pioglitazone
$30 \mathrm{mg} / \mathrm{kg}$. All the rats were subjected to these two behavioral pain tests for assessment of thermal hyperalgesia and cold allodynia on day 0 before performing surgery and subsequently $2 \mathrm{~h}$ after vehicle or pioglitazone administration on the specified days. To evaluate the post-emptive effects of pioglitazone (10 or $30 \mathrm{mg} / \mathrm{kg}$, i.p., once daily) on maintenance of neuropathic pain symptoms in CCI rats, treatment was initiated on day 14 after surgery and continued for two weeks. Further, in the antagonist studies, separate groups of CCI rats were administered BADGE alone (30 mg/kg, i.p.) or BADGE (30 mg/kg, i.p.) $30 \mathrm{~min}$ before pioglitazone (30 mg/kg, i.p., two weeks) administration. Sham-operated and nerve-injured control animals (CCI control) received equal volume of vehicle before the nociceptive stimulus. The response to behavioral nociceptive tests was assessed on days $0,7,14,17,21,24$ and 28 following surgery.

\section{Behavioral test paradigm \\ Assessment of cold allodynia}

The withdrawal latency $(\mathrm{sec})$ to non-noxious thermal stimulus when hind paws dipped in water bath maintained at $10 \pm 0.5^{\circ} \mathrm{C}$ was recorded. Baseline paw withdrawal latency (PWL) to cold stimulation was assessed thrice giving 5 min intervals and averaged. A cut off time of $15 \mathrm{sec}$ was maintained. A significant reduction in PWL indicates allodynia. ${ }^{17}$

\section{Assessment of thermal hyperalgesia}

The mean PWL (sec) to thermal stimulation was measured by dipping the paw in water bath maintained at $47 \pm 0.5^{\circ} \mathrm{C}$. The baseline PWL was assessed three times giving $5 \mathrm{~min}$ interval and averaged. A cut off time of $15 \mathrm{sec}$ was maintained. The significant change in the PWLs from the basal responses was considered as hyperalgesia. ${ }^{18}$

\section{Plasma extravasation}

Evans blue dye (EB) intravenous (i.v., in the caudal tail vein) injection (75 mg/kg i.v.) was used to measure plasma extravasation. On day 28 after surgery, rats were injected EB one hour after vehicle or pioglitazone treatment. Rats were sacrificed by cervical dislocation after one hour, and their ipsilateral and contralateral paws were removed. Plasma extravasion was determined as described by La Rana et al. with slight modifications. Both hind paws (ipsi- and contralateral) were divided separately into sections and extracted with $4 \mathrm{~mL}$ of formamide for $72 \mathrm{~h}$ and measured the absorbance at $550 \mathrm{~nm}$. These values were obtained using a standard curve in order to determine the amount of EB dye in each sample and are indicated as $\mu \mathrm{g} \mathrm{EB} / \mathrm{g}$ tissue. ${ }^{19}$

\section{Collection of sciatic nerve}

After the behavioral tests on day 28, the animals were sacrificed via cervical dislocation. Ipsilateral sciatic nerve of each rat was collected for the assessment of markers of nitroso-oxidative stress and inflammation. The isolated sciatic nerve was weighed, homogenized in ice cold phosphate buffer $\mathrm{pH} 7.0$ and divided in to two portions. One part of the homogenate was centrifuged for $15 \mathrm{~min}$ at $2000 \mathrm{~g}$ to obtain the clear supernatant for the assessment of nitroso-oxidative stress markers and another part of homogenate was mixed $4 \mu \mathrm{L} / \mathrm{mL}$ protease inhibitor cocktail. These samples were centrifuged at $14,000 \mathrm{~g}$ at $4^{\circ} \mathrm{C}$ for $15 \mathrm{~min}$ and the supernatant was used for assessment of pro-inflammatory cytokines.

\section{Assessment of pro-inflammatory cytokines}

The supernatant of sciatic nerve homogenate was used for assessment of IL- $1 \beta$ and TNF- $\alpha$ level. Samples are estimated using the quantitative sandwich enzyme immunoassay according to manufacturer's instructions (R\&D systems, MN, USA). The cytokine level was determined by 
comparing samples to the standard curve generated from the respective kits at $450 \mathrm{~nm}$ and are indicated as $\mathrm{pg} / \mathrm{mg}$ wet weight of sciatic nerve.

\section{Assessment of markers of oxidative stress}

Lipid peroxidation was assessed colorimetrically by the method of Niehaus and Samuelson and indicated as nmol/g tissue. ${ }^{20}$ Protein carbonyls content was determined by a method described by Levine and indicated as $\mu$ mole/g tissue. ${ }^{21}$ Reduced glutathione (GSH) level was assessed by a method described by Lou et al. and indicated as $\mu$ mole/g tissue. ${ }^{22}$ Activities of catalase and superoxide dismutase (SOD) were measured by the methods of Aebi, and Misra and Fridovich, respectively and indicated as $\%$ activity of sham control. ${ }^{23,24}$ The nitrite concentration was measured by the Griess reaction and indicated as nmole/g tissue..$^{25}$

\section{Statistical analysis}

The results are expressed as mean \pm standard error of mean of $\mathrm{n}$ (number of animals studied) observations. The data were analyzed using one way analysis of variance followed by Tukey test for multiple comparisons. $P$-value less than 0.05 (typically $\leq 0.05$ ) was considered statistically significant.

\section{RESULTS}

\section{Chronic constriction injury and induction of neuropathy}

The baseline paw withdrawal response of each rat in each test on day 0 was quite consistent and exhibited no significant variance. All the rats showed normal body weight and general motor activity after surgery throughout the duration of the study (Data not shown). Throughout the observation period, the ipsi-and contralateral paw withdrawal responses to cold and thermal stimuli in sham-operated rats were unaltered from baseline values. The contralateral paw withdrawal responses in CCI control rats were not significantly different compared to sham-operated rats (Data not shown). Day 3 onwards, the ipsilateral PWLs of all the nerve-injured rats were significantly less than sham-operated rats indicating the development of neuropathic pain and attained steady state between days 14 and 28 after surgery indicating the maintenance of neuropathic pain state in a time-dependent manner (Figure 1 and 2).

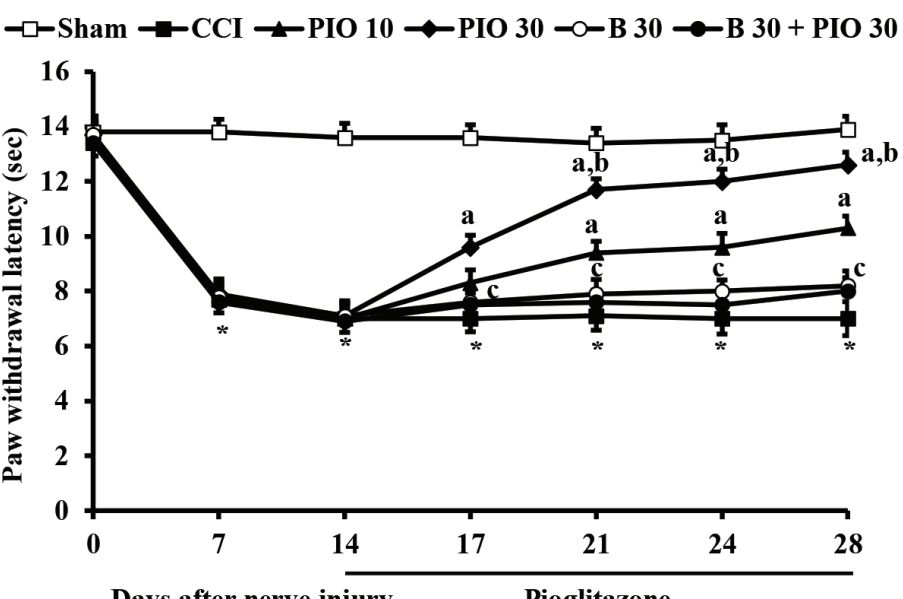

Days after nerve injury Pioglitazone

Figure 1: Effect of post-emptive pioglitazone on ipsilateral paw withdrawal latencies to cold stimuli in chronic constriction injury (CCI) rats. PIO: Pioglitazone (10 or $30 \mathrm{mg} / \mathrm{kg}$ ); B 30: BADGE $30 \mathrm{mg} / \mathrm{kg}$. Values are mean \pm SEM. ${ }^{*} P<0.05$ vs Sham control; a $P<0.05$ vs $C C l$ control; ${ }^{b} P<0.05$ vs $P I O ~ 10$; c $P<0.05$ vs PIO 30.

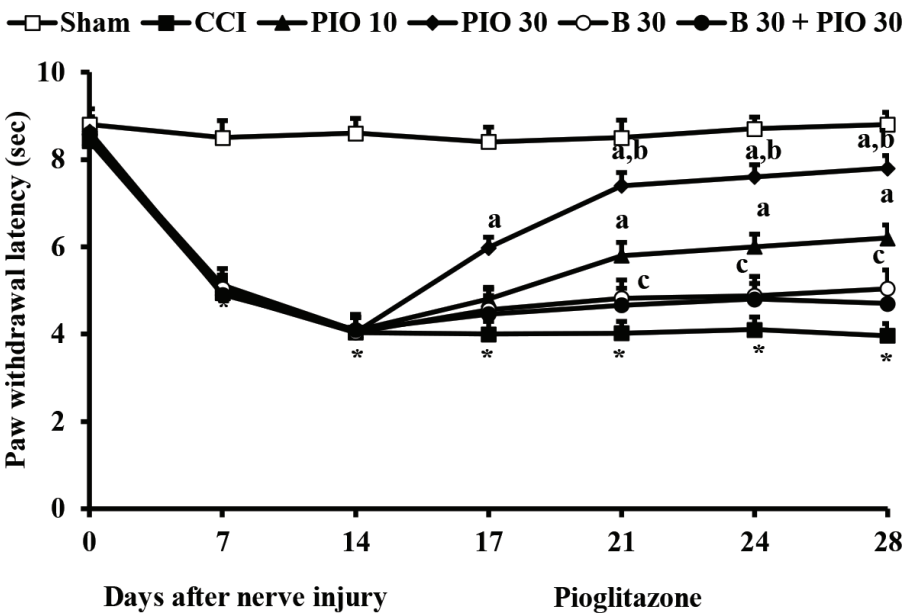

Figure 2: Effect of post-emptive pioglitazone on ipsilateral paw withdrawal latencies to thermal stimuli in chronic constriction injury $(\mathrm{CCl})$ rats. PIO: Pioglitazone (10 or $30 \mathrm{mg} / \mathrm{kg}$ ); B 30: BADGE $30 \mathrm{mg} / \mathrm{kg}$. Values are mean \pm SEM. ${ }^{*} P<0.05$ vs Sham control; a $P<0.05$ vs $C C l$ control; ${ }^{b} P<0.05$ vs $P I O 10$; C $P<0.05$ vs PIO 30.

\section{Effect of pioglitazone on cold allodynia and thermal} hyperalgesia in $\mathrm{CCl}$ rats

Chronic systemic administration of pioglitazone (10 or $30 \mathrm{mg} / \mathrm{kg}$ ) doseand time-dependently reversed the established pain hypersensitivities, cold allodynia and thermal hyperalgesia, in the ipsilateral paws of CCI rats (Figure 1 and 2). To assess whether these antiallodynic and antihyperalgesic effects of pioglitazone were receptor dependant, rats received BADGE, a PPAR- $\gamma$ antagonist, $(30 \mathrm{mg} / \mathrm{kg}$, i.p.) $30 \mathrm{~min}$ before pioglitazone administration for two weeks. BADGE alone was without any effect; however, the effects of pioglitazone $(30 \mathrm{mg} / \mathrm{kg})$ were significantly blocked by pre-administration of BADGE in nerve-injured rats on day 28 (Figure 1 and 2). In all these treatment groups, pioglitazone with or without BADGE did not alter the contralateral PWLs in these behavioral tests as compared to CCI rats (data not shown).

\section{Effect of pioglitazone on plasma extravasation in $\mathrm{CCl}$ rats}

Nerve injured rats showed increased vascular permeability as measured by increased Evans blue extravasation in ipsilateral paw as compared to sham-operated rats. However, there was no significant difference in Evans blue extravasation between contralateral paws of sham-operated and CCI rats. Administration of pioglitazone (10 or $30 \mathrm{mg} / \mathrm{kg}$ ) during the maintenance of neuropathic state significantly and dose-dependently reduced the plasma extravasation in ipsilateral paw of nerve injured rats in comparison to that of CCI control rats (Figure 3). BADGE alone $(30 \mathrm{mg} / \mathrm{kg}$, i.p.) had no effect on capillary permeability in CCI rats. Administration of BADGE (30 mg/kg) before pioglitazone $(30 \mathrm{mg} / \mathrm{kg})$ treatment significantly reduced the effect of pioglitazone on plasma extravasation (Figure 3). On the other hand, pioglitazone had no effect on plasma extravasation in the contralateral paw of CCI rats at any dose as compared to CCI control rats (Figure 3).

\section{Effect of pioglitazone on pro-inflammatory cytokines in $\mathrm{CCl}$ rats}

The levels of TNF- $\alpha$ and IL- $1 \beta$ were significantly elevated in ipsilateral sciatic nerve of CCI rats as compared to that of sham-operated rats. In CCI rats, administration of pioglitazone (10 or $30 \mathrm{mg} / \mathrm{kg}$ ) dosedependently and significantly abrogated the increased levels of TNF-a 


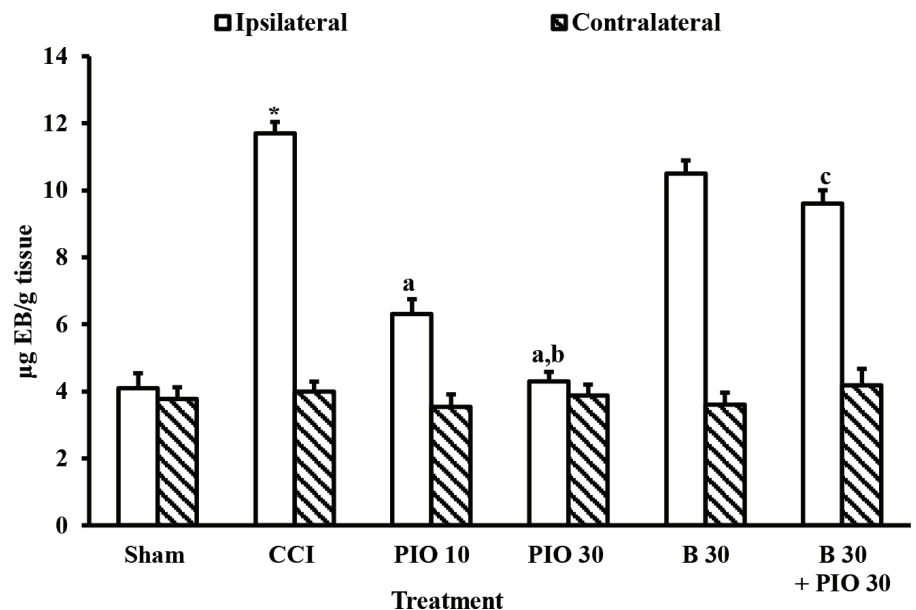

Figure 3: Effect of post-emptive pioglitazone on plasma extravasation in chronic constriction injury $(\mathrm{CCl})$ rats.

PIO: Pioglitazone (10 or $30 \mathrm{mg} / \mathrm{kg}$ ); B 30: BADGE $30 \mathrm{mg} / \mathrm{kg}$. Values are mean \pm SEM. ${ }^{*} P<0.05$ vs Sham control; a $P<0.05$ vs $C C l$ control; ${ }^{\text {b }} P<0.05$ vs $\mathrm{PIO} 10$; c $P<0.05$ vs $\mathrm{PIO} 30$.

Table 1: Effect of post-emptive pioglitazone on tumor necrosis factor- $a$ (TNF- $\alpha$ ) and interleukin-1 $\beta$ (IL-1 $\beta$ ) in chronic constriction injury (CCI) rats.

\begin{tabular}{ccc}
\hline Group & $\begin{array}{c}\text { TNF- } a \\
(\mathrm{pg} / \mathrm{mg} \text { weight })\end{array}$ & $\begin{array}{c}\text { IL-1 } \beta \\
(\mathbf{p g} / \mathrm{mg} \text { weight })\end{array}$ \\
\hline Sham control & $77.8 \pm 8.1$ & $95.8 \pm 9.9$ \\
CCI control & $360.3 \pm 28.3^{*}$ & $425.2 \pm 25.6^{*}$ \\
PIO 10 & $236.8 \pm 17.3^{\mathrm{a}}$ & $289.6 \pm 24.2^{\mathrm{a}}$ \\
PIO 30 & $103.9 \pm 12.4^{\mathrm{a}, \mathrm{b}}$ & $123.7 \pm 17.4^{\mathrm{a}, \mathrm{b}}$ \\
B 30 & $340.8 \pm 20.5$ & $439.8 \pm 23.1$ \\
B 30 + PIO 30 & $333.5 \pm 27.3^{\mathrm{c}}$ & $412.3 \pm 22.9^{\mathrm{c}}$ \\
\hline
\end{tabular}

PIO: Pioglitazone (10 or $30 \mathrm{mg} / \mathrm{kg}$ ); B 30: BADGE $30 \mathrm{mg} / \mathrm{kg}$. Values are mean \pm SEM. ${ }^{a} p<0.05$ vs Sham control; ${ }^{a} p<0.05$ vs CCI control; ${ }^{b} p<0.05$ vs PIO 10 ; ${ }^{c} p<0.05$ vs PIO 30.

and IL- $1 \beta$ in injured sciatic nerve as compared CCI control rats. Though BADGE alone $(30 \mathrm{mg} / \mathrm{kg}$, i.p.) had no effect, but pretreatment of rats with BADGE $(30 \mathrm{mg} / \mathrm{kg})$ markedly reduced the effects of pioglitazone $(30 \mathrm{mg} / \mathrm{kg}$ ) on pro-inflammatory cytokines in the ipsilateral sciatic nerve of CCI rats (Table 1).

\section{Effect of pioglitazone on the markers of oxidative and nitrosative stress in $\mathrm{CCl}$ rats}

Following sciatic nerve injury, there was a marked increase in levels of nitroso-oxidative stress markers accompanied by marked reduction in antioxidant defenses in comparison to sham-surgery (Table 2 and 3). Post-emptive pioglitazone (10 or $30 \mathrm{mg} / \mathrm{kg}$ ) significantly and dosedependently reduced nerve-injury-induced elevated levels of lipid peroxidation, protein carbonyls, and nitrite (Table 2), improved the depleted level of GSH, and restored diminished activities of SOD and catalase (Table 3) in comparison to that of CCI control rats. BADGE (30 mg/kg, i.p.) alone did not alter nitroso-oxidative stress markers, whereas pretreatment with BADGE significantly reduced pioglitazonemediated antioxidant effect (Tables 2 and 3).
Table 2: Effect of post-emptive pioglitazone on TBARS, protein carbonylation and nitrite levels in chronic constriction injury (CCI) rats.

\begin{tabular}{cccc}
\hline $\begin{array}{c}\text { Treatment } \\
(\mathrm{mg} / \mathrm{kg})\end{array}$ & $\begin{array}{c}\text { TBARS } \\
(\mathrm{nmole} / \mathrm{g} \text { tissue })\end{array}$ & $\begin{array}{c}\text { Protein } \\
\text { carbonylation } \\
(\mu \text { mole/g tissue) }\end{array}$ & $\begin{array}{c}\text { Nitrite } \\
(\mathrm{nmole} / \mathrm{g} \text { tissue })\end{array}$ \\
\hline Sham control & $79.13 \pm 14.76$ & $1.27 \pm 0.17$ & $92.12 \pm 11.27$ \\
CCI control & $337.71 \pm 25,23^{*}$ & $4.03 \pm 0.35^{*}$ & $331.45 \pm 24.68^{*}$ \\
PIO 10 & $187.81 \pm 11.38^{\mathrm{a}}$ & $2.14 \pm 0.19^{\mathrm{a}}$ & $195.57 \pm 11.51^{\mathrm{a}}$ \\
PIO 30 & $101.35 \pm 9.85^{\mathrm{a}, \mathrm{b}}$ & $1.50 \pm 0.13^{\mathrm{a}, \mathrm{b}}$ & $137.89 \pm 10.91^{\mathrm{a}, \mathrm{b}}$ \\
B 30 & $319.67 \pm 21.58$ & $4.17 \pm 0.48$ & $313.54 \pm 21.72$ \\
B 30 + PIO 30 & $302.71 \pm 19.97^{\mathrm{c}}$ & $3.98 \pm 0.29^{\mathrm{c}}$ & $319.71 \pm 18.79^{\mathrm{c}}$ \\
\hline
\end{tabular}

TBARS: Thiobarbituric acid reacting substances; PIO: Pioglitazone (10 or $30 \mathrm{mg} / \mathrm{kg}$ ); B 30: BADGE $30 \mathrm{mg} / \mathrm{kg}$. Values are mean \pm SEM. ${ }^{*} p<0.05$ vs Sham control; ${ }^{\mathrm{a}} p<0.05$ vs CCI control; ${ }^{\mathrm{b}} p<0.05$ vs PIO $10 ;^{\mathrm{c}} p<0.05$ vs PIO 30.

Table 3: Effect of pre-emptive pioglitazone on GSH, SOD, and catalase in chronic constriction injury $(\mathrm{CCI})$ rats.

\begin{tabular}{cccc}
\hline $\begin{array}{c}\text { Treatment } \\
(\mathrm{mg} / \mathrm{kg})\end{array}$ & $\begin{array}{c}\text { GSH } \\
\text { ( } \begin{array}{c}\text { Smole/g } \\
\text { tissue) }\end{array}\end{array}$ & $\begin{array}{c}\text { SOD } \\
\text { (\% Sham } \\
\text { control) }\end{array}$ & $\begin{array}{c}\text { Catalase } \\
\text { (\% Sham } \\
\text { control) }\end{array}$ \\
\hline Sham control & $4.91 \pm 0.37$ & $100.02 \pm 6.69$ & $99.68 \pm 9.17$ \\
CCI control & $2.18 \pm 0.18^{*}$ & $44.51 \pm 4.24^{*}$ & $35.51 \pm 3.11^{*}$ \\
PIO 10 & $3.17 \pm 0.16^{\mathrm{a}}$ & $63.57 \pm 5.01^{\mathrm{a}}$ & $69.14 \pm 5.17^{\mathrm{a}}$ \\
PIO 30 & $4.18 \pm 0.31^{\mathrm{a}, \mathrm{b}}$ & $87.12 \pm 6.85^{\mathrm{a}, \mathrm{b}}$ & $86.21 \pm 6.89^{\mathrm{a}, \mathrm{b}}$ \\
B 30 & $2.07 \pm 0.21$ & $42.61 \pm 3.41$ & $38.17 \pm 3.44$ \\
B 30 + PIO 30 & $2.23 \pm 0.18^{\mathrm{c}}$ & $41.77 \pm 3.73^{\mathrm{c}}$ & $41.26 \pm 3.87^{\mathrm{c}}$ \\
\hline
\end{tabular}

GSH: Reduced glutathione; SOD: Superoxide dismutase; PIO: Pioglitazone (10 or $30 \mathrm{mg} / \mathrm{kg}$ ); B 30: BADGE $30 \mathrm{mg} / \mathrm{kg}$. Values are mean \pm SEM. " $p<0.05$ vs Sham control; ${ }^{\mathrm{a}} p<0.05$ vs CCI control; ${ }^{\mathrm{b}} p<0.05$ vs PIO $10{ }^{c} p<0.05$ vs PIO 30.

\section{DISCUSSION}

Neuropathic pain involves nociceptive processing and central sensitization in the sensory nervous system due to neuronal damage leading to pain hypersensitivity primarily manifested as allodynia and hyperalgesia. We observed that nerve-injured rats displayed time-dependent development and sustained maintenance of neuropathic pain state that persisted for days after the surgery. Post-emptive administration of pioglitazone, a PPAR- $\gamma$ agonist, dose-dependently attenuated the established pain hypersentivities. Of note, more marked antinociceptive effect of pioglitazone was observed with the high dose. In addition to this, post-emptive pioglitazone had not altered basal responses to cold and thermal stimuli in contralateral paws indicating that the observed effects were not due to hypoalgesic effects of pioglitazone. Evidence exist that pioglitazone per se is not associated with any change in basal nociceptive responses as well as did not elicit hypoalgesic effects in naïve animals. ${ }^{26}$ Several studies emphasized effects of PPAR- $\gamma$ agonists in modulating chronic pain, ${ }^{4}$ diabetes, ${ }^{15}$ and chemotherapy-induced neuropathic pain. ${ }^{26,27}$ Recently, Li et al. demonstrated that intrathecal infusion oflentivirus encoding PPAR- $\gamma$ attenuated neuropathic pain. ${ }^{28}$ Adding to this, pioglitazone readily cross blood-brain barrier and showed neuroprotection in the CNS. ${ }^{14,29}$ Further, in order to elucidate receptor dependent effects of pioglitazone, BADGE, a PPAR- $\gamma$ antagonist was employed. In is observed that pre-treatment with BADGE blocked the beneficial antiallodynic and antihyperalgesic effects of pioglitazone. In addition, pioglitazone treatment had no effect on body weight gain and general motor activity during the entire study period suggesting that the antiallodynic and antihyperalgesic effects of pioglitazone were not due to any effect on developmental and behavioral 
changes. These results strongly demonstrate a role of PPAR- $\gamma$ activation in nociception and further emphasizing on its potential as effective modulator of neuropathic pain.

Essentially, the lack of effective treatment for neuropathic pain is partly due to its complex and poorly understood molecular mechanisms and in part by therapeutic paradigms targeting on one specific intervention for pain relief. ${ }^{1,3}$ Therefore, we attempted to understand mechanisms involved in potential antinociceptive effects of pioglitazone. The estimation of plasma extravasation, which is an indicator of peripheral inflammation measured as leakage of Evans blue gives an account on increased perineuronal capillary permeability in the paws of injured nerve. Following nerve injury, afferent fibers releases neuroactive peptides, such as substance $\mathrm{P}$ and calcitonin-gene related peptide as well as inflammatory mediators, such as prostaglandins and nitric oxide at the peripheral site leads to increased vascular permeability and consequently leakage of plasma fluid. ${ }^{19}$ In the present study, pioglitazone reduced plasma extravasation in the paws ipsilateral, but not contralateral to nerve-injury. Importantly, BADGE blocked the anti-inflammatory effect of pioglitazone. The underlying mechanism of this beneficial effect of pioglitazone remains elusive with the present data. Compelling evidence indicates nerve injury induces infiltration and recruitment of inflammatory cells, such as mast cells, macrophages, and neutrophils at the site of nerve injury which evoke perineuronal inflammation..$^{5-7]}$ It is also supported by the fact that PPAR- $\gamma$ are expressed on mast cell, macrophages and neutrophils ${ }^{30,31}$ and activation of PPAR- $\gamma$ inhibits inflammatory cell infiltration. ${ }^{31,32}$ Thus, it is plausible that activation of PPAR- $\gamma$ might result in reduced inflammatory cell infiltration and plasma leakage which abolished peripheral inflammation following nerve injury.

To elucidate other periphery mechanisms responsible for antinociceptive effects of PPAR- $\gamma$ activation, we also estimated pro-inflammatory cytokines in the injured nerves. Accumulating data indicates that nerve injury causes the activation of macrophages, microglia and Schwann cells that augment the release of pro-inflammatory cytokines. ${ }^{7,33}$ Of particular note, pro-inflammatory cytokines directly excites sensory neurons, causes central sensitization and exaggerated pain states as well. ${ }^{34}$ Indeed, pro-inflammatory cytokines and their upstream and downstream signaling play a role in inflammation after nerve injury and critical for the development and sustained maintenance of neuropathic pain state. ${ }^{7,34,35}$ The most striking finding of the study is that post-emptive administration of pioglitazone reduced TNF- $\alpha$ and IL- $1 \beta$ levels in injured nerves that parallels with attenuation of neuropathic pain hypersensitivities. Adding to this, antinociceptive effects of pioglitazone were reversed by BADGE revealing that PPAR- $\gamma$ activation is essentially required for eliciting antiinflammatory effects in the periphery. It has been reported that PPAR- $\gamma$ activation inhibits the infiltration, recruitment, and activation of neutrophils and macrophage and prevents the induction of NF- $\mathrm{BB}$ in the macrophages in an experimental model of arthritis. ${ }^{4}$ Also, PPAR- $\gamma$ activation inhibits the expression of various inflammatory proteins such as inducible nitric oxide synthase, cyclooxygenase- 2 , chemokines, and pro-inflammatory cytokines, IL- $1 \beta$ and TNF- $\alpha$, in particular. ${ }^{4,26,27}$ Several studies reported ameliorative effects of PPAR- $\gamma$ agonists against chronic inflammation in the periphery. ${ }^{4,26,36}$ In addition to this, peripherally released chemokines and cytokines dysregulates the blood-spinal cord permeability ${ }^{37}$ and evoke the influx of inflammatory mediators into spinal cord. ${ }^{6,37}$ Therefore, central mechanisms, particularly PPAR- $\gamma$ mediated anti-inflammatory effects in spinal cord cannot be ignored. Though, we had not measured inflammation in the CNS following nerve injury, evidence exist that PPAR- $\gamma$ activation reduces microglial activation and pro-inflammatory cytokines levels in dorsal root ganglion, brain and spinal cord, the important sites for pain processing. ${ }^{26,27,38}$
Indeed, pioglitazone cross blood-brain barrier and showed protection in various CNS insults associated with inflammation. ${ }^{14,38}$ Thus, in line with recent findings in the spinal cord along with peripheral effects observed in the present study demonstrates that anti-inflammatory effects due to PPAR- $\gamma$ activation strongly contributed to extenuation of behavioral pain hypersensitivity after nerve injury.

Compelling evidence indicates nitroso-oxidative stress play a crucial role in neuropathic pain. ROS and metabolites of free radicals-mediated lipid and protein oxidation are known to cause neuronal hypersensitivity following tissue injury. ${ }^{10,11}$ In addition, ROS and peroxynitrite mediate NF- $\kappa B$ activation and increases gene expression of pro-inflammatory cytokines and together cause central sensitization. ${ }^{39,40}$ Therefore, we also measured nitoso-oxidative stress markers to delineate mechanisms that would abrogate detrimental effects of free radicals. It is observed that pioglitazone reduced oxidative stress and nitrite level and improved antioxidant defenses in injured sciatic nerve. Several agents that modulate oxidative stress and scavenge free radicals showed protective effects and alleviated neuropathic state. ${ }^{9,41,42}$ Furthermore, activation of PPAR- $\gamma$ caused neuroprotection by improving the antioxidant defense factors, such as GSH, SOD, catalase, and glutathione peroxidase. ${ }^{4,26,38}$ It has been reported that catalase and SOD gene promoters contain the PPRE indicating that they are directly regulated by PPAR $-\gamma \cdot{ }^{43,44}$ Adding to this, agents that targeted activation of PPAR- $\gamma$ resulted in activation of endogenous cellular antioxidant signaling pathways which include nuclear factor-erythroid 2-related factor (Nrf2) and hemeoxygenase-1 (HO-1), inhibiting HMGB-1/RAGE, Rac1/ROS, and canonical Wingless-Int (Wnt)/ $\beta$-catenin pathways, thereby increase in the antioxidant defense in neurons, DRGs, and spinal glial cells..$^{13,27,45}$ Of note, the protective effects of pioglitazone were mitigated by PAPR- $\gamma$ antagonist in ipsilateral, but not contralateral paws of mononeuropathic rats. Thus, these data and along with the results of the present study support the evidence that pharmacological activation of PPAR- $\gamma$ is associated with inhibitory effect on nitroso-oxidative stress that contributes to amelioration of neuropathic pain due to nerve injury.

\section{CONCLUSION}

To conclude, in this work we show that post-emptive administration of pioglitazone reduced established pain hypersensitivity accompanied by mechanisms contributing to marked reduction in plasma extravasation, neuroinflammation and oxidative stress that were blocked by PPAR- $\gamma$ antagonist. Together, our data strongly suggest that PPAR- $\gamma$ activation exerted anti-inflammatory as well as antioxidant mechanisms in extenuating neuropathic pain due to sciatic nerve injury.

\section{Author Contributions}

Conceptualization, ST, SP; Methodology, ST, HP, SP; Investigation, ST, HP; Data analysis, ST, HP; Validation, ST, HP, SP; Writing-original draft, ST, HP; Writing-review and editing, ST, HP, SK, SP. All authors take responsibility for appropriate content, critically revised the manuscript, and approved the version of the manuscript to be published.

\section{ACKNOWLEDGEMENT}

We thank the management of ISF College of Pharmacy, Moga, Punjab and Bharat Institute of Technology-Pharmacy, Hyderabad for providing the necessary facilities for completion of the study.

\section{CONFLICT OF INTEREST}

The authors declare no conflict of interest. 


\section{ABBREVIATIONS}

BADGE: Bisphenol A diglycidyl ether; CCI: Chronic constriction injury; EB: Evans blue; GSH: Reduced glutathione; IL: Interleukin; PIO: Pioglitazone; PPAR- $\gamma$ : Peroxisome proliferator-activated receptor- $\gamma$; PWL: Paw withdrawal latency; SOD: Superoxide dismutase; TNF- $\alpha$ : Tumor necrosis factor- $\alpha$.

\section{REFERENCES}

1. Bouhassira D. Neuropathic pain: definition, assessment and epidemiology. Rev Neurol (Paris). 2019;175(1-2):16-25. doi: 10.1016/j.neurol.2018.09.016, PMID 30385075 .

2. Blyth FM. Global burden of neuropathic pain. Pain. 2018;159(3):614-7. doi: 10.1097/j.pain.0000000000001127, PMID 29447139

3. Moisset X, Bouhassira D, Avez Couturier J, Alchaar H, Conradi S, Delmotte MH, Lanteri-Minet M, Lefaucheur JP, Mick G, Piano V, Pickering G, Piquet E, Regis C, Salvat E, Attal N. Pharmacological and non-pharmacological treatments for neuropathic pain: systematic review and French recommendations. Rev Neurol (Paris). 2020;176(5):325-52. doi: 10.1016/j.neurol.2020.01.361, PMID 32276788.

4. Ruiz-Miyazawa KW, Staurengo-Ferrari L, Pinho-Ribeiro FA, Fattori $\bigvee$, Zaninelli TH, Badaro-Garcia S, et al. 15d-PGJ2-loaded nanocapsules ameliorate experimental gout arthritis by reducing pain and inflammation in a PPAR-gamma-sensitive manner in mice [sci rep:2018:8(1):13979].

5. Saleem M, Deal B, Nehl E, Janjic JM, Pollock JA. Nanomedicine-driven neuropathic pain relief in a rat model is associated with macrophage polarity and mast cell activation. Acta Neuropathol Commun. 2019;7(1):108. doi: 10.1186/s40478-019-0762-y, PMID 31277709

6. Kiguchi N, Kobayashi D, Saika F, Matsuzaki S, Kishioka S. Inhibition of peripheral macrophages by nicotinic acetylcholine receptor agonists suppresses spinal microglial activation and neuropathic pain in mice with peripheral nerve injury. J Neuroinflammation. 2018:15(1):96. doi: 10.1186/s12974-018-1133-5, PMID 29587798

7. Padi SSV, Shi XQ, Zhao YQ, Ruff MR, Baichoo N, Pert CB, Zhang J. Attenuation of rodent neuropathic pain by an orally active peptide, RAP-103, which potently blocks CCR2- and CCR5-mediated monocyte chemotaxis and inflammation. Pain. 2012;153(1):95-106. doi: 10.1016/j.pain.2011.09.022, PMID 22033364.

8. Uslusoy F, Nazıroglu M, Çig B. Inhibition of the TRPM2 and TRPV1 Channels through Hypericum perforatum in sciatic nerve injury-induced rats demonstrates their key role in apoptosis and mitochondrial oxidative stress of sciatic nerve and dorsal root ganglion. Front Physiol. 2017;8:335. doi: 10.3389/fphys.2017.00335, PMID 28620309.

9. Ilari S, Giancotti LA, Lauro F, Gliozzi M, Malafoglia V, Palma E, Tafani M, Russo MA, Tomino C, Fini M, Salvemini D, Mollace V, Muscoli C. Natural antioxidant control of neuropathic pain-exploring the role of mitochondrial SIRT3 pathway. Antioxidants (Basel). 2020;9(11):1103. doi: 10.3390/antiox9111103, PMID 33182469

10. Bittar A, Jun J, La JH, Wang J, Leem JW, Chung JM. Reactive oxygen species affect spinal cell type-specific synaptic plasticity in a model of neuropathic pain. Pain. 2017;158(11):2137-46. doi: 10.1097/j.pain.0000000000001014, PMID 28708760

11. Choi SR, Kwon SG, Choi HS, Han HJ, Beitz AJ, Lee JH. Neuronal NOS activates spinal nadph oxidase 2 contributing to central sigma-1 receptor-induced pain hypersensitivity in mice. Biol Pharm Bull. 2016:39(12):1922-31. doi: 10.1248/ bpb.b16-00326, PMID 27601184.

12. Quintão NLM, Santin JR, Stoeberl LC, Corrêa TP, Melato J, Costa R. Pharmacological treatment of chemotherapy-induced neuropathic pain: PPAR $\gamma$ agonists as a promising tool. Front Neurosci. 2019;13:907. doi: 10.3389/fnins.2019.00907, PMID 31555078.

13. Vallée A, Lecarpentier $Y$, Guillevin R, Vallée JN. Effects of cannabidiol interactions with Wnt/ $\beta$-catenin pathway and PPAR $\gamma$ on oxidative stress and neuroinflammation in Alzheimer's disease. Acta Biochim Biophys Sin (Shanghai) 2017;49(10):853-66. doi: 10.1093/abbs/gmx073, PMID 28981597.

14. Machado MMF, Bassani TB, Cóppola-Segovia V, Moura ELR, Zanata SM, Andreatini R, Vital MABF. PPAR- $\gamma$ agonist pioglitazone reduces microglial proliferation and NF-KB activation in the substantia nigra in the 6-hydroxydopamine model of Parkinson's disease. Pharmacol Rep. 2019;71(4):556-64. doi: 10.1016/j. pharep.2018.11.005, PMID 31132685.

15. Elkholy SE, Elaidy SM, El-Sherbeeny NA, Toraih EA, El-Gawly HW. Neuroprotective effects of ranolazine versus pioglitazone in experimental diabetic neuropathy: targeting Nav1.7 channels and PPAR- $\gamma$. Life Sci. 2020;250:117557. doi: $10.1016 /$ j.Ifs.2020.117557.

16. Bennett GJ, Xie YK. A peripheral mononeuropathy in rat that produces disorders of pain sensation like those seen in man. Pain. 1988;33(1):87-107. doi: 10.1016/0304-3959(88)90209-6, PMID 2837713.

17. Padi SS, Kulkarni SK. Differential effects of naproxen and rofecoxib on the development of hypersensitivity following nerve injury in rats. Pharmacol Biochem Behav. 2004;79(2):349-58. doi: 10.1016/j.pbb.2004.08.005, PMID 15501312

18. Padi SS, Jain NK, Singh S, Kulkarni SK. Pharmacological profile of parecoxib: a novel, potent injectable selective cyclooxygenase-2 inhibitor. Eur J Pharmacol. 2004;491(1):69-76. doi: 10.1016/j.ejphar.2004.03.013, PMID 15102535.

19. La Rana G, Russo R, D’Agostino G, Sasso O, Raso GM, lacono A, Meli R, Piomelli D, Calignano A. AM404, an anandamide transport inhibitor, reduces plasma extravasation in a model of neuropathic pain in rat: role for cannabinoid receptors. Neuropharmacology. 2008:54(3):521-9. doi: 10.1016/j.neuropharm.2007.10.021, PMID 18093621.

20. Niehaus Jr WG Samuelsson B. Formation of malonaldehyde from phospholipid arachidonate during microsomal lipid peroxidation. Eur $\mathrm{J}$ Biochem. 1968;6(1):126-30. doi: 10.1111/j.1432-1033.1968.tb00428.x, PMID 4387188.

21. Levine $R L$, Garland D, Oliver $C N$, Amici A, Climent I, Lenz AG, Ahn BW, Shaltiel S, Stadtman ER. Determination of carbonyl content in oxidatively modified proteins. Methods Enzymol. 1990;186:464-78. doi: 10.1016/00766879(90)86141-h, PMID 1978225

22. Lou MF, Dickerson JE Jr, Garadi R, York BM Jr. Glutathione depletion in the lens of galactosemic and diabetic rats. Exp Eye Res. 1988;46(4):517-30. doi: 10.1016/ s0014-4835(88)80009-5, PMID 3133235

23. Aebi H. Catalase in vitro. Methods Enzymol. 1984;105:121-6. doi: 10.1016/ s0076-6879(84)05016-3, PMID 6727660

24. Misra HP, Fridovich I. The role of superoxide anion in the autoxidation of epinephrine and a simple assay for superoxide dismutase. J Biol Chem. 1972;247(10):3170-5. doi: 10.1016/S0021-9258(19)45228-9, PMID 4623845

25. Sastry KV, Moudgal RP, Mohan J, Tyagi JS, Rao GS. Spectrophotometric determination of serum nitrite and nitrate by copper-cadmium alloy. Anal Biochem. 2002;306(1):79-82. doi: 10.1006/abio.2002.5676, PMID 12069417.

26. Pasupulati H, Padi SSV, Dodoala S, Koganti PVSRG. Nuclear PPAR- $\gamma$ activation modulates inflammation and oxidative stress in attenuating chemotherapy-induced neuropathic pain in vivo. J Pharm Res Int. 2021;33(38B):167-79.

27. Zhou YQ, Liu DQ, Chen SP, Chen N, Sun J, Wang XM, Li DY, Tian YK, Ye DW. PPAR $\gamma$ activation mitigates mechanical allodynia in paclitaxel-induced neuropathic pain via induction of Nrf2/HO-1 signaling pathway. Biomed Pharmacother 2020;129:110356. doi: 10.1016/j.biopha.2020.110356.

28. Li X, Guo Q, Ye Z, Wang E, Zou W, Sun Z, He Z, Zhong T, Weng Y, Pan Y. PPAR Prevents neuropathic pain by down-regulating CX3CR1 and attenuating M1 activation of microglia in the spinal cord of rats using a sciatic chronic constriction injury model. Front Neurosci. 2021;15:620525. doi: 10.3389/fnins.2021.620525.

29. Grommes C, Karlo JC Caprariello A Blankenship D, Dechant A Landreth GE. The PPAR $\gamma$ agonist pioglitazone crosses the blood-brain barrier and reduces tumor growth in a human xenograft model. Cancer Chemother Pharmacol. 2013:71(4):929-36. doi: 10.1007/s00280-013-2084-2, PMID 23358645.

30. Yao Q, Liu J, Zhang Z, Li F, Zhang C, Lai B, Xiao L, Wang N. Peroxisome proliferatoractivated receptor $\gamma(P P A R \gamma)$ induces the gene expression of integrin $\alpha \vee \beta 5$ to promote macrophage M2 polarization. J Biol Chem. 2018;293(43):16572-82. doi: 10.1074/jbc.RA118.003161, PMID 30181212

31. Hasegawa-Moriyama $M$, Kurimoto $T$, Nakama $M$, Godai K, Kojima $M$ Kuwaki T, Kanmura Y. Peroxisome proliferator-activated receptor-gamma agonist rosiglitazone attenuates inflammatory pain through the induction of heme oxygenase-1 in macrophages. Pain. 2013;154(8):1402-12. doi: 10.1016/j. pain.2013.04.039, PMID 23707273

32. Zhang Y, Li X, Fang S, Zhu Z, Yao M, Ying L, Zhu L, Ma Z, Wang W. Peroxisome proliferator-activated receptor $\gamma$ agonist suppresses mast cell maturation and induces apoptosis. Mol Med Rep. 2017;16(2):1793-800. doi: 10.3892/ mmr.2017.6802, PMID 28656266.

33. Chu LW, Cheng KI, Chen JY, Cheng YC, Chang YC, Yeh JL, Hsu JH, Dai ZK, Wu BN. Loganin prevents chronic constriction injury-provoked neuropathic pain by reducing TNF- $\alpha / \mathrm{IL}-1 \beta$-mediated NF- $\mathrm{KB}$ activation and Schwann cell demyelination. Phytomedicine. 2020;67:153166. doi: 10.1016/j.phymed.2019.153166.

34. Ji RR, Nackley A, Huh Y, Terrando N, MaixnerW. Neuroinflammation and central sensitization in chronic and widespread pain. Anesthesiology. 2018;129(2):343-66 doi: 10.1097/ALN.0000000000002130, PMID 29462012

35. Lee $S$, Shi $X Q$, Fan A, West B, Zhang J. Targeting macrophage and microglia activation with colony stimulating factor 1 receptor inhibitor is an effective strategy to treat injury-triggered neuropathic pain. Mol Pain. 2018;14:1744806918764979. doi: 10.1177/1744806918764979, PMID 29546785

36. Takahashi $Y$, Hasegawa-Moriyama M, Sakurai T, Inada E. The macrophagemediated effects of the peroxisome proliferator-activated receptor-gamma agonist rosiglitazone attenuate tactile allodynia in the early phase of neuropathic pain development. Anesth Analg. 2011;113(2):398-404. doi: 10.1213/ ANE.0b013e31821b220c, PMID 21490083.

37. Echeverry S, Shi XQ, Rivest S, Zhang J. Peripheral nerve injury alters blood-spinal cord barrier functional and molecular integrity through a selective inflammatory pathway. J Neurosci. 2011;31(30):10819-28. doi: 10.1523/JNEUROSCI.1642-11.2011, PMID 21795534.

38. Wen L, You W, Wang H, Meng Y, Feng J, Yang X. Polarization of microglia to the $M 2$ phenotype in a peroxisome proliferator-activated receptor gammadependent manner attenuates axonal injury induced by traumatic brain injury in mice. J Neurotrauma. 2018 Oct 1;35(19):2330-40. doi: 10.1089/neu.2017.5540, PMID 29649924.

39. Doyle T, Chen Z, Muscoli C, Bryant L, Esposito E, Cuzzocrea S, Dagostino C Ryerse J, Rausaria S, Kamadulski A, Neumann WL, Salvemini D. Targeting the 
overproduction of peroxynitrite for the prevention and reversal of paclitaxelinduced neuropathic pain. J Neurosci. 2012;32(18):6149-60. doi: 10.1523/JNEUROSCI.6343-11.2012, PMID 22553021.

40. Yin Q, Fan Q, Zhao Y, Cheng MY, Liu H, Li J, Lu FF, Jia JT, Cheng W, Yan CD. Spinal $\mathrm{NF}-\mathrm{\kappa B}$ and chemokine ligand 5 expression during spinal glial cell activation in a neuropathic pain model. PLOS ONE. 2015;10(1):e0115120. doi: 10.1371/journal. pone.0115120, PMID 25635831.

41. Biijem KR, Padi SS, lal Sharma P. Pharmacological activation of heme oxygenase (HO)-1/carbon monoxide pathway prevents the development of peripheral neuropathic pain in Wistar rats. Naunyn Schmiedebergs Arch Pharmacol. 2013;386(1):79-90. doi: 10.1007/s00210-012-0816-1, PMID 23224421

42. Chen $H$, Xie K, Chen $Y$, Wang $Y$, Wang $Y$, Lian N, Zhang K, Yu Y. Nrf2/HO-1 signaling pathway participated in the protection of hydrogen sulfide on neuropathic pain in rats. Int Immunopharmacol. 2019;75:105746. doi: 10.1016/j. intimp.2019.105746.

43. Khoo NK, Hebbar S, Zhao W, Moore SA, Domann FE, Robbins ME. Differential activation of catalase expression and activity by PPAR agonists: implications for astrocyte protection in anti-glioma therapy. Redox Biol. 2013;1(1):70-9. doi: 10.1016/j.redox.2012.12.006, PMID 24024139.

44. Takagi T, Naito Y, Mizushima K, Hirai Y, Kamada K, Uchiyama K, Handa O, Ishikawa T, Itoh Y. 15-deoxy- $\Delta 12,14$-prostaglandin J2 ameliorates dextran sulfate sodium-induced colitis in mice through heme oxygenase-1 induction. Arch Biochem Biophys. 2019 Nov 30;677:108183. doi: 10.1016/j.abb.2019.108183.

45. Xia P, Pan Y, Zhang F, Wang N, Wang E, Guo Q, Ye Z. Pioglitazone Confers Neuroprotection Against Ischemia-Induced Pyroptosis due to its Inhibitory Effects on HMGB-1/RAGE and Rac1/ROS Pathway by Activating PPAR- $\gamma$. Cell Physiol Biochem. 2018;45(6):2351-68. doi: 10.1159/000488183, PMID 29554649.

Article History: Submission Date : 28-07-2021; Revised Date : 11-08-2021; Acceptance Date : 10-09-2021.

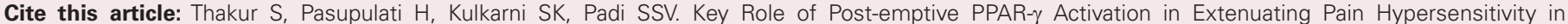
Mononeuropathic Rats. Int. J. Pharm. Investigation. 2021;11(3):312-8. 